\title{
To drink or not to drink: the role of automatic and controlled cognitive processes in the etiology of alcohol-related problems
}

Citation for published version (APA):

Wiers, R. W. H. J., Houben, K. M. P. I., Smulders, F. T. Y., Conrod, P., \& Jones, B. (2006). To drink or not to drink: the role of automatic and controlled cognitive processes in the etiology of alcohol-related problems. In R. W. H. J. Wiers, \& A. W. Stacy (Eds.), Handbook of implicit cognition and addiction (pp. 339-361). SAGE. Cognitive psychology program https://doi.org/10.4135/9781412976237.N22

Document status and date:

Published: 01/01/2006

DOI:

10.4135/9781412976237.N22

Document Version:

Publisher's PDF, also known as Version of record

Document license:

Taverne

Please check the document version of this publication:

- A submitted manuscript is the version of the article upon submission and before peer-review. There can be important differences between the submitted version and the official published version of record.

People interested in the research are advised to contact the author for the final version of the publication, or visit the DOI to the publisher's website.

- The final author version and the galley proof are versions of the publication after peer review.

- The final published version features the final layout of the paper including the volume, issue and page numbers.

Link to publication

\footnotetext{
General rights rights.

- You may freely distribute the URL identifying the publication in the public portal. please follow below link for the End User Agreement:

www.umlib.nl/taverne-license

Take down policy

If you believe that this document breaches copyright please contact us at:

repository@maastrichtuniversity.nl

providing details and we will investigate your claim.
}

Copyright and moral rights for the publications made accessible in the public portal are retained by the authors and/or other copyright owners and it is a condition of accessing publications that users recognise and abide by the legal requirements associated with these

- Users may download and print one copy of any publication from the public portal for the purpose of private study or research.

- You may not further distribute the material or use it for any profit-making activity or commercial gain

If the publication is distributed under the terms of Article $25 \mathrm{fa}$ of the Dutch Copyright Act, indicated by the "Taverne" license above, 
C H A P T E R

\title{
To Drink or Not
}

to Drink: The Role of

Automatic and Controlled

Cognitive Processes in the Etiology

of Alcohol-Related Problems

\author{
Reinout W. Wiers, Katrijn Houben, Fren T. Y. Smulders, \\ Patricia J. Conrod, and Barry T. Jones
}

\begin{abstract}
Explicit measures revealed three basic types of alcohol-related cognitions: positive reinforcement, negative reinforcement (relief), and negative expectancies. Using the same typology, we review studies assessing alcohol-related cognitions with implicit measures. Most research focused on automatic appetitive responses (positive reinforcement). The common model is that an automatic appetitive response tendency can be inhibited by more controlled inhibitory processes. In addition, there is scattered evidence indicating a role for automatic aversive responses to alcohol. Negative reinforcement appears to be more difficult to assess with tests involving single associations. It is argued that the reason is that for negative reinforcement two associations are needed (negative affect $<>$ alcohol $<>$ positive affect). Findings are integrated into a model from which suggestions for interventions are given.
\end{abstract}

S tudies investigating alcohol-related cognitions with explicit measures have identified three basic types of alcoholrelated cognitions: positive reinforcement (e.g., fun), negative reinforcement (relief from negative affect), and negative expectancies (negative outcomes of drinking). The first two variables have been documented as positive predictors of prospective drinking, and the last as a negative predictor of

AUTHOR'S NOTE: The first author is funded by "VIDI" grant 452.02 .005 , from the Dutch National Science Foundation (N.W.O.). The authors wish to thank Brian Ostafin, Tibor Palfai, Sherry Stewart, Werner Stritzke, Andrew Waters, and Martin Zack for helpful comments on the manuscript. 
prospective drinking that could be related to motivation to cut down drinking (e.g., If I continue drinking like this, I'll lose my job). In this chapter, we will review the recent literature using implicit or indirect measures (see De Houwer, Chapter 2) to assess alcoholrelated cognitions using this typology. Central questions are:

1. Are the same three types of cognitions found in research using implicit measures?

2. Do implicit and explicit cognitions predict unique variance in drinking behavior and/or unique aspects of drinking behavior?

3. Do implicit and explicit alcohol-related cognitions relate to different or to the same underlying processes?

4. How do individual differences in personality relate to the development of implicit and explicit alcohol-related cognitions?

A model is presented that integrates the findings, followed by implications for interventions. First, we discuss some issues that emerged from alcohol research using explicit measures, relevant for the discussion of the findings with more implicit measures.

\section{EXPLICIT ALCOHOL- RELATED COGNITIONS}

The explicit assessment of alcohol-related cognitions has been undertaken from a variety of different theoretical frameworks. Most dominant has been the expectancy framework, proposed by Goldman and colleagues (e.g., Brown et al., 1980; Goldman et al., 1999). Other influential frameworks have been social learning theory (Bandura, 1977), cognitive behavioral therapy (e.g., Beck et al., 1993; Marlatt \& Gordon, 1985), the theories of reasoned action and planned behavior (Ajzen, 1988; Fishbein \& Ajzen, 1975), and motivational theories (Cooper et al., 1995; Cox \& Klinger, 1988). Despite differences in the exact definitions of alcoholrelated cognitions in these frameworks, some general issues emerged.

The first general issue concerns whether assessment should be unipolar or bipolar. In the attitude literature, bipolar assessment is common. An example is:

(E1.) Drinking alcohol is:

good — bad.

(good and bad need to be on the same line.)

The underlying assumption of bipolar assessment is that the endpoints are opposites (correlated - 1), which, in case of attitudes, could reflect a natural tendency to classify something as either positive or as negative and not both at the same time (e.g., Russell \& Carroll, 1999). This view has been challenged, because people have been found to be ambivalent about some attitude objects, with alcohol being a prime example (e.g., Conner \& Sparks, 2002; note that ambivalence is at the heart of some addiction theories, e.g., Orford, 2001). In expectancy research, unipolar measures were found to better predict alcohol use than bipolar measures (Leigh, 1989). It has become standard practice to use unipolar response scales including both positive and negative expectancies (Fromme et al., 1993; Leigh \& Stacy, 1993; Wiers et al., 1997). An example item:

(E2.) After a few drinks I feel good disagree —_ agree.

It should be noted that a bipolar view on emotional valence and the finding that alcohol-related cognitions are best measured in a unipolar way are not necessarily incompatible: The time frame of negative and positive expectancies is different, with negative expectancies referring to more distal events (Dunn \& Earleywine, 2001; Goldman et al., 
1999; Jones \& McMahon, 1994), and higher dosages of alcohol (Fromme et al., 1993; Wiers et al., 1997). Hence, even though the uni- or bipolar nature of affect remains controversial (Cacioppo \& Berntson, 1994; Russell \& Carroll, 1999), it is clear that people hold both positive and negative alcohol-related cognitions, with the positive cognitions usually relating to immediate and negative cognitions to later outcomes.

The second issue concerns how many specific factors or dimensions are needed to represent alcohol-related cognitions. In the attitude literature, typically only positive and negative cognitions are assessed, whereas in the expectancy and motivation literature more specific factors have been proposed (e.g., Brown et al., 1980; Cooper, 1994). For positive expectancies, Leigh and Stacy (1993) and Goldman et al. (1997) showed that specific first-order expectancy factors (e.g., sexual and social enhancement) increased the prediction of alcohol use above the general higher-order factor(s). This suggests that it is useful to assess alcohol-related cognitions in more detail than general positive and negative factors only.

An important distinction in the expectancy and motivation literature concerns positive versus negative reinforcement, where the difference involves the emotional antecedent of drinking: positive or negative mood, respectively (e.g., Cooper, 1994). The literature on negative reinforcement motivations has indicated that negative reinforcement (or coping) motivations are strong positive predictors of alcohol problems (e.g., Cooper et al., 1995; Stewart et al., 2002). These findings may reflect the "clinical wisdom" that alcohol use often becomes problematic once individuals begin to drink to escape problems, which results in more negative affect in the long run (Sher, 1991).

With respect to the third type of alcohol cognitions, negative expectancies are usually found to be negatively correlated with current drinking in cross-sectional research in social drinkers (e.g., Goldman et al., 1999; Wiers et al., 1997). Jones and McMahon (1994) have found that negative expectancies predict success of abstinence of alcoholics in treatment. From this perspective, negative expectancies develop with negative experiences and should be positively correlated with (negative) prior drinking experience. Still, they should negatively predict (future) drinking and should be related to motivation to change behavior (Jones \& McMahon, 1998). Recently, it has been shown that it is useful to assess motivations for refraining from drinking next to motivations to use alcohol (like negative expectancies, McEvoy et al., 2004). Finally, it may be useful to assess motivation for alternative behaviors from drinking (see Cox et al., Chapter 17).

In expectancy research, Goldman and colleagues have investigated the underlying memory structure of expectancies using multidimensional scaling (MDS; Goldman et al., 1999; Rather et al., 1992). A twodimensional structure was selected reflecting two orthogonal dimensions: valence (positive vs. negative) and arousal (arousal vs. sedation). Goldman et al. (1999) observed that these dimensions also underlie affective processing, and that many expectancies can be regarded as anticipated changes in affect. Mapping of subgroups of drinkers into the two-dimensional, valence-arousal space, showed that all drinkers were on the positive side, and that the more people drink, the higher they score on the arousal dimension (Goldman et al., 1999). In a recent paper, Goldman and Darkes (2004) argued that specific expectancy factors can all be conceptualized as unique positions in the twodimensional, valence-arousal space. A problem with this notion is the location of negative reinforcement as positive sedation, which is associated with light rather than with heavy drinking, whereas negative reinforcement motives are predictors of problem drinking. In 
conclusion, more factors or dimensions are needed than valence alone to represent alcohol-related cognitions, but the exact number of factors needed is an issue of debate.

Third, a general concern about the explicit assessment of alcohol-related cognitions and the prediction of drinking concerns criterion contamination (Stewart \& Devine, 2000; cf. Darkes et al., 1998). When people drink a lot, they are likely to respond positively to general items like "I drink because it's fun" (Cooper, 1994). This may assess selfjustifications rather than specific alcohol cognitions. In line with this concern, the predictive power of explicit alcohol cognitions decreases markedly after controlling for previous use (e.g., Jones et al., 2001; Sher et al., 1996).

In summary, there is broad agreement that there are three types of explicit alcoholrelated cognitions: positive and negative reinforcement and negative cognitions, and they have been related to the two-dimensional structure of emotions (valence and arousal). This typology is used to review the literature on implicit alcohol-related cognitions.

\section{IMPLICIT ALCOHOL- RELATED COGNITIONS}

\section{Implicit Cognition, Positive Reinforcement, and Incentive Salience}

Most research using implicit measures to study alcohol-related cognitions also focused on positive reinforcement: attentional bias for alcohol-related cues (e.g., Bruce \& Jones, Chapter 10; Jones et al., 2002), memory associations of alcohol with positive outcomes (e.g., Stacy, 1997; Stacy et al., Chapter 6), with positive reinforcement (e.g., Kramer \& Goldman, 2003), with positive arousal (e.g., Wiers, Van Woerden, et al., 2002), and with approach action tendencies (e.g., Palfai
\& Ostafin, 2003a). Findings have generally been linked to neurobiological models emphasizing incentive motivation or positive reinforcement accounts of the development and maintenance of addictive behaviors (e.g., Robinson \& Berridge, 1993, 2003; Stewart et al., 1984; Wise \& Bozarth, 1987). Findings regarding an attentional bias for alcohol are reviewed in other chapters (Bruce \& Jones, Chapter 10; Field et al., Chapter 11); here we focus on findings regarding implicit alcohol associations.

Stacy and colleagues propose that alcoholrelated associations represented in memory (e.g., positive affective outcomes related to alcohol use) can elicit a relatively automatic influence over alcohol and drug use. In a series of studies, using a variety of tests (see Stacy et al., Chapter 6), they found that the number of alcohol-related responses was predictive of higher levels of alcohol use, and this finding replicated across different measures, different populations, and different drugs of abuse (e.g., Ames \& Stacy, 1998; Stacy, 1995). Importantly, Stacy (1997) demonstrated that memory associations were the strongest predictor of prospective drinking, which remained the case after controlling for earlier use, explicit measures, and personality and background variables. Hence, this line of research has demonstrated that first associations represent unique information not captured by explicit measures. In view of the research on explicit cognitions, it is noteworthy that almost all studies in this line of research have focused on global positive associations without differentiating more specific outcomes (e.g., positive vs. negative reinforcement). A reason may be statistical power: Many participants are already needed for global positive outcomes and many more might be needed to discern specific positive outcomes.

Recently, a variety of reaction-time paradigms have been used to assess alcoholrelated cognitions, and this has been done in 
more dimensions than global positive only. In our own research, we have used adapted versions of the Implicit Association Test (IAT; Greenwald et al., 1998; also see Houben et al., Chapter 7) to assess alcohol associations in the two affective dimensions that were found in MDS alcohol and emotion research: valence and arousal. In a series of studies, we found that heavy drinkers associated alcoholic drinks more strongly with arousal than with sedation (as compared with sodas, Wiers, Ganushchack, et al., 2003; Wiers, Van de Luitgaarden, et al., 2005; Wiers, Van Woerden, et al., 2002). Alcoholarousal associations were also found in alcoholics (De Houwer et al., 2004), and light drinkers were not found to hold implicit alcohol-arousal associations (Wiers, Van Woerden, et al., 2002). On the valence dimension, all of these studies found stronger negative than positive associations for alcohol as compared with soda both for light and for heavy drinkers (in contrast with explicit positive expectancies in earlier and in the same studies). To the extent that these negative associations are "real" and not an artifact of the IAT procedure (see Houben et al., Chapter 7), we argued that this pattern of results resembles the dissociation between "wanting" and "liking" proposed by Robinson and Berridge (1993, 2003). On the basis of animal research, they distinguish between two neural processes underlying natural rewards and drug responses: "wanting" and "liking," with "liking" being an important factor in early use, and "wanting" taking over once sensitization has developed. Sensitization refers to increased psychomotor activation directly and increased incentive motivation after repeated use. Importantly, "wanting" (the activation of incentivesalience) can occur in the absence of "liking." This dissociation may reflect an important feature of addiction; that compulsive use may continue in the presence of negative effects for the individual and in the absence of pleasure
(Berridge \& Robinson, Chapter 31; Robinson \& Berridge, 1993, 2003).

We argued that the implicit arousal associations could be related either to the motivation to approach alcohol (an appetitive response, triggered by alcohol-related stimuli), or could represent a sensitized psychomotor stimulant reaction after drinking alcohol. In two recent studies, we tested these hypotheses. In the first, we found support for the first hypothesis: Implicit arousal associations (assessed with two different tests) predicted individual differences in subjective cue-induced craving assessed 6 weeks later, after controlling for background variables, habitual drinking, and memory associations assessed at the time of the cue-induced craving manipulation (Wiers, Granzier, et al., 2005). In the second study (Van den Wildenberg et al., 2004), we tested whether implicit arousal associations in heavy drinkers were correlated with heart-rate increase following rapid consumption of approximately five alcoholic drinks (a measure of sensitivity to the stimulant properties of alcohol; Conrod et al., 2001), but this was not confirmed. A caveat was the low proportion of participants with a positive family history of alcoholism, for whom the heartrate increase is strongest (Conrod et al., 2001).

Palfai and Ostafin (2003a; Ostafin et al., 2003) assessed the automatic activation of approach versus avoidance tendencies for alcohol in hazardous drinkers. This is a somewhat different approach, because it does not focus on the appraisal side of the emotion process, but on action tendencies (e.g., Frijda, 1986). Emotionally relevant cues can automatically trigger an action tendency, either toward the cue (approach) or away from the cue (avoidance). In one study, an adapted version of the IAT was used (Palfai \& Ostafin, 2003a). Categories used were alcohol versus electricity (irrelevant contrast) combined with approach versus 
avoidance. Alcohol-approach associations correlated with the frequency of binge drinking and with the number of drinks per occasion. After the assessment of the IAT and questionnaire, participants were subjected to a cue-exposure procedure. IAT approach associations were correlated with urge to drink after exposure to alcohol, but not to urge to drink at baseline. Further, after controlling for baseline responses, it was found that those who scored higher on the approach IAT, exhibited stronger urge and arousal reactivity (no reactivity for valence). These findings suggest that the approach associations in this study are closely related to the arousal associations in our own work. In a recent study (Wiers, Both, et al., 2005), we assessed both valence and arousal associations and approach-avoidance associations and found that approach avoidance associations were positively correlated with positive valence and with arousal (in the absence of a correlation between valence and arousal). This suggests that approach associations are related to positive arousal associations.

The research on implicit alcohol associations presented so far has used bipolar attribute dimensions, which is at odds with the findings in the explicit literature that suggest that unipolar assessment is superior in the assessment of alcohol-related explicit cognitions (Leigh, 1989), but consistent with a bipolar view on instantaneous affect (e.g., Russell \& Carroll, 1999). Given biological research that has indicated the presence of separate neural systems for approach and avoidance (e.g., Gray, 1990; Lang, 1995), it may be useful to assess implicit alcohol associations in a unipolar manner too. This has been done in a number of recent studies. Jajodia and Earleywine (2003) separately assessed positive and negative associations (against different neutral categories) using an adapted IAT and found both positive and negative associations for alcohol. Positive but not negative associations predicted unique variance in alcohol use, but this finding has to be qualified for two reasons: Positive associations were always assessed first (and IAT effects get smaller with practice; see Wiers, Van de Luitgaarden, et al., 2005) and in the regression analysis positive associations were entered first. Houben and Wiers (2004) assessed positive, negative, arousal, and sedation associations in a series of (counterbalanced) unipolar IATs. We found the strongest effects for negative associations (effect size, $d>1$ ), large effects for both positive and arousal associations ( $d$ around .8 ), and smaller but significant sedation associations ( $d$ around .5). Note that these findings are in line with the findings with the bipolar IATs (negative stronger than positive and arousal stronger than sedation). Interestingly, only arousal associations were significantly correlated with alcohol use and problems. These first results using unipolar IATs are promising, but it should be noted that choice of the opposing contrast category is difficult and may influence results (see De Houwer, 2002; Houben et al., Chapter 7). Using a (unipolar) primed Stroop task, Kramer and Goldman (2003) found significant positivearousal associations in heavy drinkers and significant sedation associations in light drinkers. Ostafin et al. (2003) used a priming task to assess (unipolar) approach and avoidance tendencies. Hazardous drinkers classified target words with respect to approach or avoidance, and the targets were preceded by briefly-shown alcohol-related or neutral primes. The results on both dimensions (difference between neutral and alcohol primed approach and avoidance words) ranged from very positive to very negative $(-340 \mathrm{~ms}$ to $480 \mathrm{~ms}$ ), which may indicate stronger approach tendencies in some individuals and stronger avoidance tendencies in others. Weak avoidance and not strong approach motivations predicted binge drinking and alcohol-related problems. The authors note, however, that the negative finding for 
approach motivations is qualified by the low reliability of the priming procedure. Hence, unipolar implicit assessment of alcohol-related cognitions shows promise. Different associations, including emotional dimensions (valence, arousal), outcomes of drinking, and action tendencies (approach vs. avoidance) can be assessed. The latter could be assessed more directly (actual movement toward or away from the stimulus; cf. Mogg et al., 2003).

Some studies investigated the effects of a priming dose of alcohol on implicit alcohol cognitions. Palfai and Ostafin (2003b) assessed primed positive and negative associations for alcohol as compared with neutral targets. Participants performed the task twice, before and after a priming dose of alcohol or placebo. It was found that the consumption of alcohol as compared with placebo made the positive associations with alcohol particularly salient. Similarly, consumption of a moderate dose of alcohol has been found to increase the activation of an alcohol-memory bias, assessed as the number of alcoholrelated associations to ambiguous words (Glautier \& Spencer, 1999; Havermans et al., 2004). Further, after an alcoholic sip-prime, alcohol-related words of positive affect were found to be more accessible in social drinkers (e.g., Jones \& Schulze, 2000). Hence, drinking a low dose of alcohol enhances the accessibility in memory of positive reinforcement associations and approach tendencies (see Fillmore \& Vogel-Sprott, Chapter 20; de Jong et al., Chapter 27).

In summary, researchers using a variety of techniques have found that in heavy drinkers, alcohol-related cues automatically grab and hold attention (Bruce \& Jones, Chapter 10; Field et al., Chapter 11), and that they are automatically associated with (positive) arousal and approach action tendencies. These findings have been related to biological theories that focus on positive reinforcement and incentive motivation. In line with this, it has been found that alcoholrelated cues and priming dosages make the implicit alcohol-related cognitions more salient, and that implicit alcohol associations predict cue-induced craving.

\section{Implicit Negative Associations?}

As reviewed above, there is accumulating evidence that with increasing alcohol use, people develop stronger appetitive reactions to alcohol including automatic approach tendencies. It is also evident that most people reduce alcohol consumption in their twenties, often without professional help even after high levels of consumption (e.g., Sher \& Gotham, 1999). The question is what restrains their drinking. One factor concerns reduced opportunities to drink and increased responsibilities, but there is also evidence that alcohol-related cognitions play a role. When a person increasingly experiences problems related to drinking, this will be a motivator to change behavior (Jones \& McMahon, 1998; Orford, 2001). From this perspective, the problem drinker is torn between two forces: an automatic approach reaction triggered by alcohol-related cues and a more controlled inhibitory response that is motivated by more distal negative outcomes (Stacy et al., 2004; Tiffany, 1990; Wiers, de Jong, et al., 2004; Wiers, Van Woerden, et al., 2002).

An additional possibility is that at least in some individuals, with repeated negative experiences, automatic negative associations develop that give rise to an automatic avoidance response. Note that an attentional bias for alcohol-related stimuli has generally been interpreted as a marker of an appetitive response, but could also be related to an automatic avoidance reaction, similar to findings in anxiety research (e.g., Stormark et al., 1997; see also de Jong et al., Chapter 27 and Field et al., Chapter 11).

Two studies examined associative memory responses to negative next to positive 
alcohol-related outcomes (Gadon et al., 2004; Leigh \& Stacy, 1998). Leigh and Stacy found that previous alcohol use predicted undergraduates' associative memory responses to both positive and negative outcomes of drinking. In a series of studies, Gadon et al. (2004) developed an association instrument including frequent and infrequent positive and negative alcohol-related outcomes as well as nonalcohol-related outcomes. They found that undergraduate students' alcohol responses to highly frequent positive and negative outcomes correlated with their alcohol use. A subsequent study using the same methodology in older adults replicated this finding. In the latter sample, negative low-frequency, alcohol-related outcomes and even negative outcomes unrelated to alcohol generated more alcohol responses. This finding suggests that maturing out of heavy use might be related to increased accessibility of negative alcohol associations with age.

Some of the findings with reaction-time measures discussed in the previous section can also be interpreted as suggestive evidence for the existence of automatic negative or avoidance associations. The first concerns the replicated finding of strong negative associations in heavy drinkers in valence IATs (De Houwer et al., 2004; Houben \& Wiers, 2004; Wiers, Ganushchack, et al., 2003; Wiers, Granzier, et al., 2003; Wiers, Van de Luitgaarden, et al., 2005; Wiers, Van Woerden, et al., 2002). Even though the finding is reliable, it should be noted that heavy drinkers do not hold stronger negative associations than light drinkers (if anything they tend to be somewhat less negative; cf. Waters \& Sayette, Chapter 21). Further, we found that negative associations did not correlate with alcoholrelated problems, while arousal associations did (Houben \& Wiers, 2004; Wiers, Van de Luitgaarden, et al., 2005). Findings with a different reaction-time test to assess associations (the Extrinsic Affective Simon
Task, or EAST; De Houwer, 2003) showed that alcohol was associated as strongly with negative as with positive valence in heavy drinkers (no significant difference; De Houwer et al., 2004; Wiers, Ganushchack, et al., 2003). Because the EASTs used were bipolar, however, it remains possible that heavy drinkers hold both positive and negative associations. The findings regarding the large variance in automatic approach versus avoidance associations (Palfai \& Ostafin, 2003a; Ostafin et al., 2003) also leave the possibility open that automatic avoidance associations may develop, either in some individuals or within one individual next to automatic approach associations (which would lead to "implicit ambivalence").

Is there other evidence in favor of automatic avoidance reactions? Before the current interest in implicit cognition and addiction, there was a research tradition on aversion conditioning, with the first experiments dating back to the 1920s (Nathan, 1985). The clinical literature can be summarized as "success and failure" (Nathan, 1985): success primarily for chemical aversion therapy (which is a biologically more related to negative response than shocks; Garcia, 1989), with higher one-year abstinence levels than usual in alcohol treatment. Failure concerns the lack of controlled studies, and the fact that most studies were performed in private clinics with high-SES (social economic status) alcoholics with good motivation for change (Nathan, 1985; Wilson, 1987, 1991). Some findings in this line of research are interesting for the present topic (automatic aversive reactions to alcohol).

A series of studies by Baker and Cannon (Baker \& Cannon, 1979; Cannon et al., 1986) demonstrated that aversion therapy resulted in specific changes in subjective, behavioral, and physiological responses specific to alcohol (compared with sodas) that were consistent with acquired aversion (e.g., more negative flavor rating, overt signs of 
disgust, and accelerated cardiac response). The latter variable predicted the latency to the first drink (Cannon et al., 1986). Elkins (1991), following Garcia (1989), notes that taste aversion conditioning should be seen as different from classical conditioning, which subserves the learning of cognitive expectancies, and that "neither conscious mediation nor intentionality are necessary for CA [consummatory aversion] formation" (Elkins, 1991, p. 393). In his reply, Wilson (1991) agrees with Elkins (1991) that taste aversion is a form of Evaluative Conditioning (EC) that should be seen as an automatic process different from classical conditioning. A recent review concluded that EC is indeed a different process than classical conditioning (De Houwer et al., 2001): EC is resistant to extinction, less influenced by statistical contingency, does not require conscious awareness of the co-occurrence of neutral and emotional events, and is not modulated by occasion setting (context effects).

A final line of research relevant for the discussion of automatic approach versus aversion tendencies is research on cue reactivity, in which a variety of physiological measures have been assessed. A meta-analysis by Carter and Tiffany (1999) concluded that physiological responses were generally more in line with incentive models (approach tendencies). It may be questioned, however, to what extent the physiological data unequivocally support incentive models: One interpretation of the results (Glautier, 1999) is that emotionally relevant cues give rise to autonomic arousal (increased heart rate and skin conductance) and that this can lead either to an appetitive or to an aversive response (or perhaps both, in case of "implicit ambivalence"). This might be an explanation for the diversity of the findings. Further, a number of methodological issues need to be addressed in this area of research including a standardization of procedures (Stritzke et al., 2004), because subtle variations may dramatically change the effects (e.g., holding vs. sipping alcohol generates opposite response patterns; Glautier et al., 1992). Grüsser and colleagues (2002) used the affective modulation of the startle response as a measure of affective valence (Lang, 1995) in response to aversive, neutral, appetitive, and alcohol-related pictures. These responses were compared with subjective measures of arousal, valence, and craving in detoxified alcoholics, social drinkers, and rarely-consuming controls (Grüsser et al., 2002). Abstinent alcoholics subjectively perceived the alcohol stimuli as more aversive than the social drinkers and the controls, and alcoholics and social drinkers experienced more arousal than the controls when alcohol-related stimuli were presented. Interestingly, in alcoholics, the startle data in response to alcohol stimuli were similar to the response to appetitive stimuli. Hence, the alcoholics subjectively report an aversive reaction to alcohol, but showed an automatic appetitive reaction to alcohol-related stimuli, reminiscent of the wanting versus liking dissociation proposed by Robinson and Berridge (2003). In a recent study, the mean affective startle response in a new sample of detoxified alcoholics again showed a mean positive value (Smolka et al., 2004). Interestingly, the individual startle responses showed a wide range of responses, indicating that for some the alcohol-related pictures were very aversive, whereas for others they were "better than sex" (strong appetitive response even compared with natural incentives). In summary, there is scattered evidence that indicates that at least in some people, alcohol cues can elicit an automatic aversive reaction, which is something else than an inhibition of an appetitive action tendency.

\section{Different Underlying Processes?}

In several studies and reviews of implicit cognition in substance use and misuse, it has been suggested that implicit measures may 
better tap into neurobiological processes involved in the etiology and maintenance of the addiction than explicit measures (e.g., Stacy, 1997; Stacy et al., 2004; Wiers et al., 2004; Wiers, Stacy, et al., 2002; Wiers, Van Woerden, et al., 2002). There are three lines of indirect evidence to support this notion.

First, several studies have shown that implicit associations predict unique variance in alcohol use after co-varying explicit measures (Jajodia \& Earleywine, 2003; Kramer \& Goldman, 2003; Stacy, 1997; Wiers, Van Woerden, et al., 2002). The fact that a different assessment method predicts unique variance, however, does not necessarily indicate that different processes are involved (method variance is a likely alternative). In social cognition research, it has been found that implicit measures predict different aspects of behavior than explicit measures (more spontaneous behavior; see Dovidio et al., 2001); and the same has recently been found in other areas of research, such as personality (Asendorpf et al., 2002) and psychopathology research (Huijding \& De Jong, in press; Teachman \& Woody, 2003). For example, Huijding and De Jong (in press) found that spider-related affective associations (assessed with the EAST), best predicted automatic fear responses, whereas explicit fear ratings best predicted strategic avoidance behavior. In alcohol research, there are some first indications that implicit measures predict spontaneous reactions to alcohol such as cue-induced craving (Palfai \& Ostafin, 2003a; Wiers, Granzier, et al., 2005), but more research is needed on the associations between implicit and explicit cognitions and different aspects of drinking behavior.

Second, neurobiological research demonstrated that subcortical circuits involved in emotion and motivation that are important in addiction are not directly accessible for introspection (Bechara et al., 2003; Berridge, 2001; Robinson \& Berridge, 2003; White, 1996). Implicit measures have been shown to correlate highly with activation of these structures in fMRI studies (e.g., Phelps et al., 2000). Subliminally presented pictures activate these structures in the absence of awareness (Cunningham et al., 2004). Recent research by Berridge and colleagues and by Dickinson and colleagues has demonstrated that conditioned incentive salience (underlying "wanting") can be dissociated from expected outcomes (for a review, see Berridge, 2001). Several independent studies have shown that one system can be manipulated, without affecting the other. For example, blocking the mesolimbic dopamine system blocks the incentive salience attribution but leaves the cognitive expectations unchanged, whereas prefrontal and insular lesions affect the cognitive expectations but not incentive salience (see Berridge, 2001). Again, this second line of evidence is indirect, because no direct dissociations between brain mechanisms underlying implicit versus explicit assessment of alcohol-related cognitions have been demonstrated in humans.

Third, dual-process models have been proposed in (social) cognition research (e.g., Deutsch \& Strack, Chapter 4; Evans \& Coventry, Chapter 3; Strack \& Deutsch, 2004). Common to these models is the presence of two different learning mechanisms, one fast and associative and one slower mechanism with limited capacity. Strack and Deutsch (2004) review evidence that associations are bidirectional in the fast system, whereas they are unidirectional in the slow system (e.g., expected outcomes). As noted above, different processes are likely to underlie EC and expectancy learning (De Houwer et al., 2001).

Taken together, there is indirect evidence from different lines of research that suggests that implicit measures at least partly tap into more automatic processes than explicit measures, but this should not be seen as an absolute difference (due to "leakages" between underlying processes, Berridge, 2001; Strack 


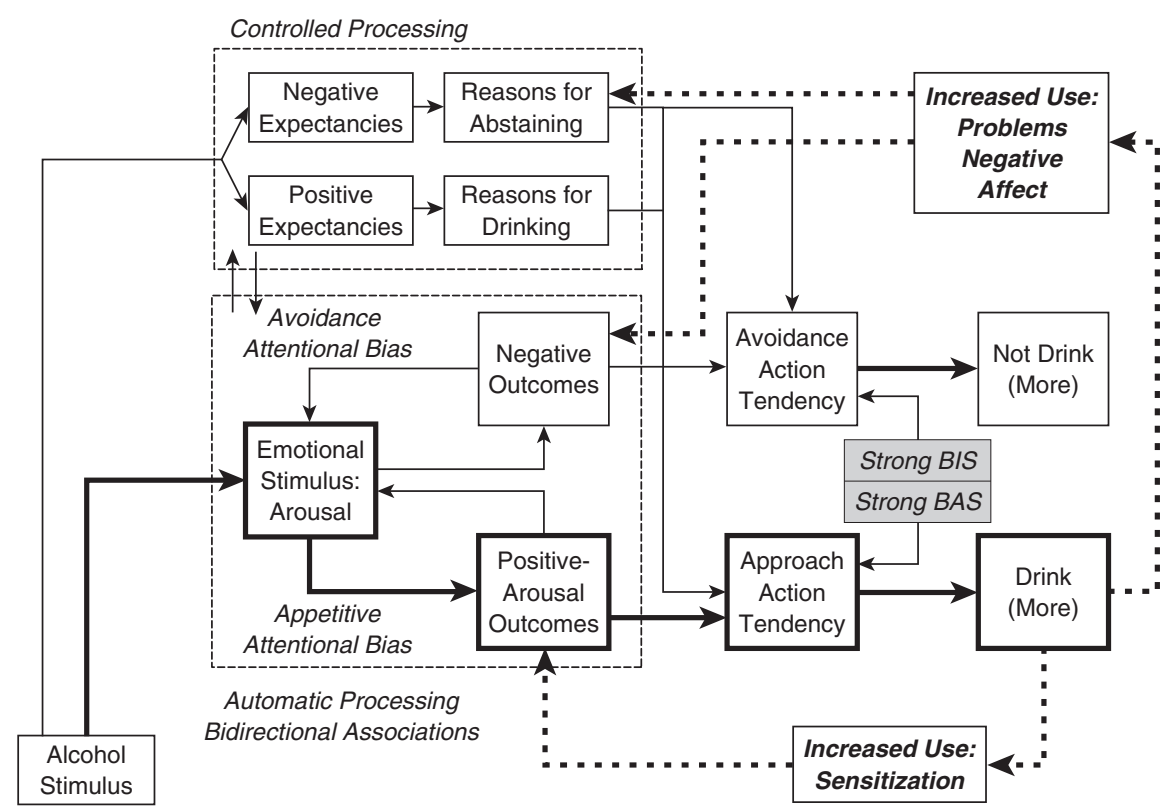

Figure 22.1 A model is depicted that attempts to integrate the findings on automatic and controlled processing in alcohol use and abuse. Thick lines develop with the development of alcohol abuse. Dashed lines are feedback loops. The upper part of the figure refers to controlled processing, with unidirectional representations. As a result of a variety of learning mechanisms (social learning, Pavlovian conditioning, expectancy learning), positive and negative expectancies develop that motivate drinking and abstaining, respectively. Meanwhile, memory associations can be formed through the mechanism of evaluative conditioning. These associations are bidirectional. As the double arrows between the two systems indicate, expectancies and associations can mutually influence each other (see Deutsch \& Strack, Chapter 4). Once an individual begins to drink regularly, neural sensitization develops which will promote automatic reactions to alcohol, such as an appetitive attentional bias for alcohol, positive arousal associations and automatically triggered approach action tendencies (bold arrows). With increased use, an individual will also experience negative effects as a result of alcohol. These experiences could lead to automatic negative associations that trigger automatic avoidance action tendencies (conditioned aversion) and in negative expectancies and reasons for abstaining. These motivations could be used to abstain from drinking or to inhibit urges to drink. (approach action tendencies). Negative reinforcement exists as a positive expectancy and reason to drink. At the automatic level a negative mood may be associated with alcohol, which in turn could activate arousal associations and approach tendencies. Finally, note that an "alcohol stimulus" can be multifaceted, with sensory elements cueing appetitive responses while other elements (e.g., health warnings) may cue avoidance responses (cf. Sherman et al., 2003).

\& Deutsch, 2004; and because measurement procedures are not entirely implicit or explicit, see De Houwer, Chapter 2). The three processes discussed so far are represented in Figure 22.1.

\section{Implicit Negative Reinforcement?}

The final issue in this section concerns the implicit assessment of negative reinforcement cognitions. The reason why this topic is 
discussed here, and not earlier, is that we propose an interpretation of the results, based on the model in Figure 22.1. It is clear that at least a subgroup of problem drinkers explicitly report to drink for reasons of negative reinforcement (stress reduction, relief from Negative Affect, NA). It is less clear to what extent these beliefs reflect actual affective changes (Greeley \& Oei, 1999). Further, several variables moderate the perceived anxiolytic effects of alcohol, such as the timing of drinking (Sayette, 1999) and a family history of alcoholism (Sher, 1987).

One important difference between the positive reinforcement and negative alcoholrelated cognitions on the one hand and the negative reinforcement cognitions on the other hand, is that an extra premise has to be added:

(I: Positive Reinforcement): Alcohol $>$ Feel good (Positive Arousal, Appetitive Response)

(II: Negative Expectancies): Alcohol > Feel bad (Negative, Sedation, Aversive Response)

(IIIa: Negative Reinforcement): Stress / NA > Alcohol > Feel good (better).

Further, as explained in the previous section, there is evidence for a fast, automatic processing mode for affective stimuli, based on relatively simple associations, in contrast to the more cognitive resources demanding explicit expectancies (Berridge, 2001; De Houwer et al., 2001). An important difference between associations and beliefs or expectancies is that expectancies and beliefs are unidirectional, whereas associations are typically bidirectional (De Houwer, 2002; Strack \& Deutsch, 2004; note, however, that the strength of the associations can be asymmetric; see McEvoy \& Nelson, Chapter 5, Stacy et al., Chapter 6). When one translates negative reinforcement expectancies into bidirectional associations, one gets:

(IIIb): Feel bad (Stress / NA) $<>$ Alcohol use $<>$ Feel good
This comes down to two associations: The first is equivalent to negative alcohol associations, the second to positive reinforcement associations. The suggestion is then that implicit (association) measures of negative reinforcement assess associations from alcohol with negative affect and with positive affect. Is this idea supported by research?

Two research groups have studied implicit negative reinforcement. These studies are discussed in more detail in Birch et al. (Chapter 18). Zack and colleagues used semantic priming tasks in which participants make a lexical decision (word/nonword) for a target (Zack et al., 1999). It was investigated to what extent a prime facilitates this process. They tested problem drinkers that were either high or low on psychiatric distress. In high but not in low psychiatric distress drinkers, they found that NA words facilitated alcohol words (NA > alcohol), and they also found the opposite facilitation (alcohol > NA), in line with the interpretation presented above.

Stewart and colleagues selected students as scoring either high on explicit negative reinforcement motives ("coping drinkers") or on positive reinforcement motives ("enhancement drinkers"). In a first study (Stewart et al., 2002), a primed Stroop task was used to investigate the effects of mood primes on the response time to alcohol or neutral words. As expected, in enhancement drinkers, positive mood cues primed alcohol words and negative mood words primed alcohol in coping drinkers. Interestingly, in coping drinkers, positive mood words also primed alcohol words. One interpretation of this finding is in line with the double bidirectional association of implicit negative reinforcement represented above (see Figure 22.1): A negative mood could activate the concept alcohol, and alcohol in turn could activate positive reinforcement associations.

Taken together, these studies generally found that in a subgroup of "coping drinkers" (selected with explicit measures) 
negative affect words automatically trigger alcohol-related concepts, which is related to their explicit reports of drinking to reduce stress or NA. The full negative reinforcement expectancies, however, cannot be "translated" into a single association, because the antecedent is a crucial part. Since associations are bidirectional, one would expect not only a NA > alcohol association, but also the reverse association (alcohol $>\mathrm{NA}$ ). Results in this area appear to be generally in line with the notion. This does not mean that implicit negative reinforcement does not exist (see also Baker et al., 2004; Curtin et al., Chapter 16), but rather that they may be difficult to assess with explicit or implicit measures using single adjectives (cf. the discussion of MDS expectancy research above). More research is needed in this area, also in relation to the actual biological effects in "coping drinkers": Do coping drinkers really medicate their negative mood and reduce their stress or not, and how is this related to physiological and implicit arousal responses? From the current perspective, the second of the two bidirectional associations involved in negative reinforcement $(\mathrm{NA}<>$ alcohol $<>$ positive mood) could be equal to the positive reinforcement association, with the difference being the cue (NA or not). In line with this idea, we recently found a significant positive correlation between implicit alcohol arousal associations and explicit negative reinforcement expectancies in heavy drinkers (Wiers, Van de Luitgaarden, et al., 2005). Further, there is some evidence that stress and alcohol both trigger the mesolimbic dopaminergic system; perhaps stress can trigger a sensitized alcohol response (Saal et al., 2003).

\section{INDIVIDUAL DIFFERENCES AND THE ETIOLOGY OF ALCOHOL USE AND PROBLEMS}

As noted above, a common view concerning the etiology and maintenance of alcohol use and abuse (and other addictive behaviors) is that there are two important cognitive processes at work: automatic appetitive action tendencies and controlled inhibitory processes. From this perspective, individual differences can be related to either one of these processes: People may differ in their appetitive action tendencies (and there is evidence for genetic differences in sensitization, Robinson \& Berridge, 2003) and individuals may differ in the ability to inhibit these action tendencies (Bechara et al., Chapter 15; Finn et al., 1994; Ostafin et al., 2003; Stacy et al., 2004). From the present perspective, there may also be individual differences in the third process involved: the development of automatic aversion with alcohol (and a genetic factor in the development of alcohol aversion has been reported; Elkins, 1986).

Recent genetic research suggests that individual differences in the susceptibility to addictive behaviors are partly substance specific and partly general (Goldman \& Bergen, 1998). With respect to the general risk factor, personality factors are a likely candidate and indeed both internalizing and externalizing behavior at age three prospectively predicted later alcoholism in boys (e.g., Caspi et al., 1996). The predictive power of externalizing behavior is relatively straightforward: This trait has been linked to a strong Behavioral Activation System (BAS), reward sensitivity, sensation seeking, behavioral undercontrol and to a weak Behavioral Inhibition System (BIS; e.g., Finn et al., 1994; Gray, 1990). Externalizing children are likely to start experimenting with alcohol early, to experience the reinforcing effects of alcohol strongly, and to lack strong inhibitory control on the urge to use. Moreover, acute and chronic alcohol and drug use significantly interfere with inhibitory control (e.g., Fillmore \& Vogel-Sprott, Chapter 20; Peterson et al., 1992).

The predictive power of internalizing personality characteristics is less straightforward 
and might involve different mechanisms. (Note that in Gray's [1990] theory BAS and BIS represent two dimensions, hence an individual may be high on BIS and on BAS, in line with the ambivalence model on alcohol motivation where an individual can differ both on approach and on avoidance tendencies; Breiner et al., 1999; see also Figure 22.1.) Once internalizing individuals initiate drinking (usually late), perceived negative reinforcement may promote an escalation of use (Conrod et al., 1998). Indeed, individual differences in anxiety sensitivity (fear of anxiety-related sensations) are associated with sensitivity to the negatively reinforcing effect of alcohol on stress responses (not expectancy mediated; see MacDonald et al., 2001).

In the development of alcohol-related cognitions, there is a crucial step: the initiation of drinking. Before this, alcohol-related cognitions are socially learned, whereas after this, genetic influences related to individual differences in the reaction to alcohol influence their further development (Wiers et al., 1998). Research using questionnaires (e.g., Fossey, 1994; Wiers et al., 1998, 2000) and first associates (Dunn \& Goldman, 2000) has shown that children report predominantly negative expectancies before they begin drinking alcohol themselves. These negative expectancies may inhibit the onset of drinking (cf. Caffray \& Schneider, 2000). Cross-sectional studies suggest that positive expectancies develop with age, which does not imply that negative expectancies diminish but rather that positive expectancies "catch up" (Cameron et al., 2003). Once drinking begins, children score higher on positive and arousal expectancies (Dunn \& Goldman, 1998, 2000), and this is more strongly the case for children of alcoholics (Wiers et al., 1998). In a recent study, Thush $\&$ Wiers (2005) tested 100 adolescents using the Single Target variety of the IAT (ST-IAT; see Houben et al., Chapter 7) and found that arousal associations and negative explicit expectancies predicted alcohol use at a oneyear follow-up. This finding suggests a causal role for (implicit) arousal associations in the early development of drinking.

Finally, personality characteristics have been related to individual differences in risk for addiction (Cloninger, 1987; Cox, 1987; Finn et al., 1994; Sher, 1991) and there is emerging evidence that personality risk factors are related to individual differences in the development of explicit alcohol-related cognitions, such as expectancies (Darkes et al., 2004) and motives (e.g., Stewart \& Devine, 2000). Explicit cognitions have been shown to partially mediate the association between personality and alcohol use (Darkes et al., 2004; Finn et al., 2000; Sher et al., 1991). Obviously, the caveat noted above (criterion contamination) is also relevant here (cf. Darkes et al., 1998). As yet, few studies have investigated the association between personality and implicit alcoholrelated cognitions. Notable exceptions are the studies on implicit cognition and negative reinforcement by Stewart and colleagues and by Zack and colleagues (see section entitled "Implicit Negative Reinforcement?" and Birch et al., Chapter 18). Further, Palfai and Ostafin (2003a) found that BAS scores correlated with implicit approach associations on the IAT, and Ostafin et al. (2003) found that more impulsive individuals had weaker primed associations between alcohol cues and avoidance words. Ames et al. (2005) found that the relationship between sensation-seeking and alcohol use and problems was mediated by implicit alcohol associations in high-risk adolescents.

In summary, individual differences in personality predict individual differences in alcohol use and abuse. There is preliminary evidence that part of this relationship is mediated by alcohol-related cognitions, but this conclusion is primarily based on research using explicit assessment strategies and on 
cross-sectional data. There clearly is a need for longitudinal studies on the development of implicit and explicit alcohol-related cognitions in relation to personality and the development of alcohol use.

\section{CONCLUSION AND IMPLICATIONS FOR INTERVENTIONS}

Individuals may differ in automatic and more controlled cognitive processes that can both influence drinking behavior. In heavy drinkers, automatic appetitive reactions triggered by alcohol cues (or by negative affect in "coping drinkers") play an important role in their drinking behavior. From the present perspective, restraint can come from two different mechanisms: an automatic mechanism that is triggered by aversion, and a more controlled effortful mechanism that inhibits an approach tendency. Interventions may target these different mechanisms. In addition, the automatization of alternative behaviors is important (Gollwitzer, 1999; see also Cox et al., Chapter 17; Prestwich et al., Chapter 29).

In treatment, it appears useful to try to decrease the automatic appetitive response (e.g., medication such as Naltrexone or cueexposure; see Wiers et al., 2004). An alternative, which has a long history but has largely gone out of favor today, is to try to stimulate an automatic avoidance reaction (aversive conditioning), but therapeutic usefulness is unclear (Wilson, 1987, 1991). Perhaps an alternative could be to use less aversive methods involving reconditioning (see De Houwer et al., 2001; Hermans \& Van Gucht, Chapter 32). Some of the implicit assessment techniques could be transformed to change automatic affective and cognitive processes in alcohol abuse (see de Jong et al., Chapter 27; Wiers et al., 2004). In addition, the more controlled inhibition mechanism may be enhanced, by making negative (long-term) expectancies more salient, by increasing motivation to change, and perhaps by automatizing restraint (see Palfai, Chapter 26). In prevention, it seems useful to try to prevent the automatic processes from taking over (see Krank \& Goldstein, Chapter 28). This could be done by stimulating the more controlled inhibitory processes, and in heavier drinkers by debunking explicit positive expectancies (e.g., through an expectancy challenge; Darkes \& Goldman, 1993; Wiers, Van de Luitgaarden, et al., 2005; Wiers, Wood, et al., 2003) and by motivational techniques (e.g., Cox et al., Chapter 17; Marlatt et al., 1998). Cognitive behavioral strategies also target implicit and explicit beliefs by explicitly challenging problematic alcohol-related beliefs, and by implicitly challenging such beliefs by building up self-efficacy around alternative coping behaviors. Whether interventions are actually achieving the cognitive effects that they are targeting is a topic of debate (see Stewart \& Conrod, in press), but will be greatly facilitated by the refinement of methods to assess alcohol cognitions. We hope this review and tentative model will stimulate further research on automatic and controlled processes in (alcohol) addiction and their applications to interventions.

REFERENCES

Ajzen, I. (1988). Attitudes, personality and behavior. Milton Keynes, UK: Open University Press.

Ames, S. L., \& Stacy, A. W. (1998). Implicit cognition in the prediction of substance use among drug offenders. Psychology of Addictive Behaviors, 12, 272-281. 
Ames, S. L., Sussman, S., Dent, C., \& Stacy, A. W. (2005). Implicit cognition and dissociative experiences as predictors of adolescent substance use. The American Journal of Drug and Alcohol Abuse, 31(1), 29-162.

Asendorpf, J. B., Banse, R., \& Mücke, D. (2002). Double dissociation between implicit and explicit personality self-concept: The case of shy behavior. Journal of Personality and Social Psychology, 83, 380-393.

Baker, T. B., \& Cannon, D. S. (1979). Taste aversion therapy with alcoholics: Techniques and evidence of a conditioned response. Behaviour Research and Therapy, 17(3), 229-242.

Baker, T. B., Piper, M. E., McCarthy, D. E., Majeskie, M. R., \& Fiore, M. C. (2004). Addiction motivation reformulated: An affective processing model of negative reinforcement. Psychological Review, 111(1), 33-51.

Bandura, A. (1977). Social learning theory. Englewood Cliffs, NJ: Prentice Hall.

Bechara, A., Damasio, A. R., \& Damasio, H. (2003). The role of the amygdale in decision-making. Annals of the New York Academy of Science, 958, 356-369.

Beck, A. T., Wright, F. D., Newman, C. F., \& Liese, B. S. (1993). Cognitive therapy of substance abuse. New York: Guilford.

Berridge, K. C. (2001). Reward learning: Reinforcement, incentives and expectations. Psychology of Learning and Motivation, 40, 223-278.

Breiner, M. J., Stritzke, W. G. K., \& Lang, A. R. (1999). Approaching avoidance. A step essential to the understanding of craving. Alcohol Research \& Health, 23, 197-206.

Brown, S. A., Goldman, M. S., Inn, A., \& Anderson, L. (1980). Expectations of reinforcement from alcohol: Their domain and relation to drinking patterns. Journal of Consulting and Clinical Psychology, 48, 419-426.

Cacioppo, J. T., \& Berntson, G. G. (1994). Relationship between attitudes and evaluative space: A critical review, with emphasis on the separability of positive and negative substrates. Psychological Bulletin, 115, 401-423.

Caffray, C. M., \& Schneider, S. L. (2000). Why do they do it? Affective motivators in adolescents' decisions to participate in risk behaviours. Cognition \& Emotion, $14,543-576$.

Cameron, C. A., Stritzke, W. G. K., \& Durkin, K. (2003). Alcohol expectancies in late childhood: An ambivalence perspective on transitions toward alcohol use. Journal of Child Psychology and Psychiatry, 44, 687-698.

Cannon, D. S., Baker, T. B., Gino, A., \& Nathan, P. E. (1986). Alcohol-aversion therapy: Relation between strength of aversion and abstinence. Journal of Consulting and Clinical Psychology, 54, 825-830.

Carter, B. L., \& Tiffany, S. T. (1999). Meta-analysis of cue-reactivity in addiction research. Addiction, 94, 327-340.

Caspi, A., Moffitt, T. E., Newman, D. L., \& Silva, P. A. (1996). Behavioral observations at age 3 years predict adult psychiatric disorders. Longitudinal evidence from a birth cohort. Archives of General Psychiatry, 53(11), 1033-1039.

Cloninger, C. R. (1987). Neurogenetic adaptive mechanisms in alcoholism. Science, 236, 410-416.

Conner, M., \& Sparks, P. (2002). Ambivalence and attitudes. European Review of Social Psychology, 12, 37-70.

Conrod, P. J., Peterson, J. B., \& Pihl, R. O. (2001). Reliability and validity of alcohol-induced heart rate increase as a measure of sensitivity to the stimulant properties of alcohol. Psychopharmacology, 157, 20-30. 
Conrod, P. J., Pihl, R. O., \& Vassileva, J. (1998). Differential sensitivity to alcohol reinforcement in groups of men at risk for distinct alcoholism subtypes. Alcoholism: Clinical and Experimental Research, 22, 585-597.

Cooper, M. L. (1994). Motivations for alcohol use among adolescents: Development and validation of a four-factor model. Psychological Assessment, 6(2), 117-128.

Cooper, M. L., Frone, M. R., Russell, M., \& Mudar, P. (1995). Drinking to regulate positive and negative emotions: A motivational model of alcohol use. Journal of Personality and Social Psychology, 69, 990-1005.

Cox, W. M. (1987). Personality theory and research. In H. T. Blane \& K. E. Leonard (Eds.), Psychological theories of drinking and alcoholism (pp. 55-89). New York: Guilford.

Cox, W. M., \& Klinger, E. (1988). A motivational model of alcohol use. Journal of Abnormal Psychology, 97, 168-180.

Cunningham, W. A., Johnson, M. K., Raye, C. L., Gatenby, J. C., Gore, J. C., \& Banaji, M. R. (2004). Separable neural components in the processing of black and white faces. Psychological Science, 15, 806-813.

Darkes, J., \& Goldman, M. S. (1993). Expectancy challenge and drinking reduction: Experimental evidence for a mediational process. Journal of Consulting and Clinical Psychology, 61, 344-353.

Darkes, J., Greenbaum, P. E., \& Goldman, M. S. (1998). Sensation-seeking disinhibition and alcohol use: Exploring issues of criterion contamination. Psychological Assessment, 10, 71-76.

Darkes, J., Greenbaum, P. E., \& Goldman, M. S. (2004). Alcohol expectancy mediation of biopsychosocial risk: Complex patterns of mediation. Experimental \& Clinical Psychopharmacology, 12, 27-38.

De Houwer, J. (2002). The Implicit Association Test as a tool for studying dysfunctional associations in psychopathology: Strengths and limitations. Journal of Behaviour Therapy and Experimental Psychiatry, 33, 115-133.

De Houwer, J. (2003). The extrinsic affective Simon task. Experimental Psychology, $50,77-85$.

De Houwer, J., Crombez, G., Koster, E. H. W., \& De Beul, N. (2004). Implicit alcohol-related cognitions in clinical samples of heavy drinkers. Journal of Behaviour Therapy and Experimental Psychiatry, 35, 275-286.

De Houwer, J., Thomas, S., \& Baeyens, F. (2001). Associative learning of likes and dislikes: A review of 25 years of research on human evaluative conditioning. Psychological Bulletin, 127, 853-869.

Dovidio, J. F., Kawakami, K., \& Beach, K. R. (2001). Implicit and explicit attitudes: Examination of the relations between measures of intergroup bias. In R. Brown \& S. Gaertner (Eds.), Blackwell handbook of social psychology: Intergroup processes (pp. 175-197). Oxford, UK: Blackwell Publishing.

Dunn, M. E., \& Earleywine, M. (2001). Activation of alcohol expectancies in memory in relation to limb of the blood alcohol curve. Psychology of Addictive Behaviors, 15, 18-24.

Dunn, M. E., \& Goldman, M. S. (1998). Age and drinking-related differences in the memory organization of alcohol expectancies in 3rd, 6th, 9th, and 12th grade children. Journal of Consulting and Clinical Psychology, 66, $579-585$. 


\section{IMPLICIT COGNITIONS AND DIFFERENT ADDICTIONS}

Dunn, M. E., \& Goldman, M. S. (2000). Validation of multidimensional scalingbased modeling of alcohol expectancies in memory: Age and drinking-related differences in expectancies of children assessed as first associates. Alcoholism: Clinical and Experimental Research, 24, 1639-1646.

Elkins, R. L. (1986). Separation of taste-aversion-prone and taste-aversion-resistant rats through selective breeding: Implications for individual differences in conditionability and aversion-therapy alcoholism treatment. Behavioral Neuroscience, $100(1), 121-124$.

Elkins, R. L. (1991). An appraisal of chemical aversion (emetic therapy) approaches to alcoholism treatment. Behaviour Research and Therapy, 29(5), 387-413.

Finn, P. R., Kessler, D. N., \& Hussong, A. M. (1994). Risk for alcoholism and classical conditioning to signals for punishment: Evidence for a weak behavioral inhibition system? Journal of Abnormal Psychology, 103, 293-301.

Finn, P. R., Sharkansky, E. J., Brandt, K. M., \& Turcotte, N. (2000). The effects of familial risk, personality, and expectancies on alcohol use and abuse. Journal of Abnormal Psychology, 109(1), 122-133.

Fishbein, M., \& Ajzen, I. (1975). Belief, attitude, intention and behavior: An introduction to theory and research. Reading, MA: Addison-Wesley.

Fossey, E. (1994). Growing up with alcohol. London: Routledge.

Frijda, N. H. (1986). The emotions. Cambridge, UK: Cambridge University Press.

Fromme, K., Stroot, E., \& Kaplan, D. (1993). Comprehensive effects of alcohol: Development and psychometric assessment of a new expectancy questionnaire. Psychological Assessment, 5, 19-26.

Gadon, L., Bruce, G., McConnochie, F., \& Jones, B. T. (2004). Negative alcohol consumption outcome associations in young and mature adult social drinkers: A route to drinking restraint? Addictive Behaviors, 29, 1373-1387.

Garcia, J. (1989). Food for Tolman: Cognition and cathexis in concert. In T. Archer $\&$ L. Nilsson (Eds.), Aversion, avoidance and anxiety: Perspectives on aversively motivated behavior (pp. 45-85). Hillsdale, NJ: Lawrence Erlbaum.

Glautier, S. (1999). Do responses to drug-related cues index appetitive or aversive states? Addiction, 94, 346-347.

Glautier, S., Drummond, D. C., \& Remington, B. (1992). Different drink cues elicit different psychophysiological responses in non-dependent drinkers. Psychopharmacology, 106, 550-554.

Glautier, S., \& Spencer, K. (1999). Activation of alcohol-related associative networks by recent alcohol consumption and alcohol-related cues. Addiction, 94, 1033-1041.

Goldman D., \& Bergen, A. (1998). General and specific inheritance of substance abuse and alcoholism. Archives of General Psychiatry, 55, 964-965.

Goldman, M. S., \& Darkes, J. (2004). Alcohol expectancy multiaxial assessment: A memory network-based approach. Psychological Assessment, 16, 4-15.

Goldman, M. S., Del Boca, F. K., \& Darkes, J. (1999). Alcohol expectancy theory: The application of cognitive neuroscience. In K. E. Leonard \& H. T. Blane (Eds.), Psychological theories of drinking and alcoholism (2nd ed., pp. 203-246). New York: Guilford.

Goldman, M. S., Greenbaum, P. E., \& Darkes, J. (1997). A confirmatory test of hierarchical expectancy structure and predictive power discriminant validation of the alcohol expectancy questionnaire. Psychological Assessment, 9, $145-157$. 
Gollwitzer, P. M. (1999). Implementation intentions. Strong effects of simple plans. American Psychologist, 54, 493-503.

Gray, J. A. (1990). Brain systems that mediate both emotion and cognition. Cognition \& Emotion, 4, 269-288.

Greeley, J., \& Oei, T. (1999). Alcohol and tension reduction. In K. E. Leonard \& H. T. Blane (Eds.), Psychological theories of drinking and alcoholism (2nd ed., pp. 14-53). New York: Guilford.

Greenwald, A. G., McGhee, D. E., \& Schwartz, J. L. K. (1998). Measuring individual differences in implicit cognition: the Implicit Association Test. Journal of Personality and Social Psychology, 74, 1464-1480.

Grüsser, S. M., Heinz, A., Raabe, A., Wessa, M., Podschus, J., \& Flor, H. (2002). Stimulus-induced craving and startle potentiation in abstinent alcoholics and controls. European Psychiatry, 17, 188-193.

Havermans, R. C., Vancleef, L., Bylois, E., Wiers, R. W., \& Jansen, A. (2004). Context dependent access to alcohol-related concepts stored in memory. Alcohol Research, 9, 219-222.

Houben, K., \& Wiers, R. W. (2004, June). Implicit alcohol associations: Influence of target category labels and contrast categories in a unipolar IAT. Paper presented at the 27th Annual Scientific Meeting of the Research Society on Alcoholism, Vancouver, BC.

Huijding, J., \& de Jong, P. J. (in press). Specific predictive power of automatic spider-related affective associations for controllable and uncontrollable fear responses toward spiders. Behaviour Research and Therapy.

Jajodia, A., \& Earleywine, M. (2003). Measuring alcohol expectancies with the Implicit Association Test. Psychology of Addictive Behaviors, 17, 126-133.

Jones, B. C., Jones, B. T., Blundell, L., \& Bruce, G. (2002). Social users of alcohol and cannabis who detect substance-related changes in a change blindness paradigm report higher levels of use than those detecting substance-neutral changes. Phychopharmacology, 165, 93-96.

Jones, B. T., Corbin, W., \& Fromme, K. (2001). A review of expectancy theory and alcohol consumption. Addiction, 91, 57-72.

Jones, B. T., \& McMahon, J. (1994). Negative and positive alcohol expectancies as predictors of abstinence after discharge from a residential treatment programme: A one- and three-month follow-up study in males. Journal of Studies on Alcohol, 55, 543-548.

Jones, B. T., \& McMahon, J. (1998). Alcohol motivations as outcome expectancies. In W. R. Miller \& N. Heather (Eds.), Treating addictive behaviors (2nd ed., pp. 75-91). New York: Plenum.

Jones, B. T., \& Schulze, D. (2000). Alcohol-related words of positive affect are more accessible in social drinkers' memory than are other words when sip-primed by alcohol. Addiction Research, 8, 221-232.

Kramer, D. A., \& Goldman, M. S. (2003). Using a modified Stroop task to implicitly discern the cognitive organization of alcohol expectancies. Journal of Abnormal Psychology, 112, 171-175.

Lang, P. J. (1995). The emotion probe. Studies of motivation on alcohol. American Psychologist, 50, 372-385.

Leigh, B. C. (1989). In search of the seven dwarves: Issues of measurement and meaning in alcohol expectancy research. Psychological Bulletin, 105, 361-373. 
Leigh, B. C., \& Stacy, A. W. (1993). Alcohol outcome expectancies: Scale construction and predictive utility in higher order confirmatory factor models. Psychological Assessment, 5, 216-229.

Leigh, B. C., \& Stacy, A. W. (1998). Individual differences in memory associations involving the positive and negative outcomes of alcohol use. Psychology of Addictive Behaviors, 12, 39-46.

MacDonald, A. B., Stewart, S. H., Hutson, R., Rhyno, E., \& Lee Loughlin, H. (2001). The roles of alcohol and alcohol expectancy in the dampening of responses to hyperventilation among high anxiety sensitive young adults. Addictive Behaviors, 26, 841-867.

Marlatt, G. A., Baer, J. S., Kivlahan, D. R., Dimeff, L. A., Larimer, M. E., Quigley, L. A., et al. (1998). Screening and brief intervention for high-risk college student drinkers: Results from a 2-year follow-up assessment. Journal of Consulting and Clinical Psychology, 66, 604-615.

Marlatt, G. A., \& Gordon, J. R. (1985). Relapse prevention: Maintenance strategies in the treatment of addictive behaviors. New York: Guilford.

McEvoy, P. M., Stritzke, W. G. K., French, D. J., Lang, A. R., \& Ketterman, R. L. (2004). Comparison of three models of alcohol craving in young adults: A cross validation. Addiction, 99, 482-497.

Mogg, K., Bradley, B. P., Field, M., \& De Houwer, J. (2003). Eye movements to smoking-related pictures in smokers: Relationship between attentional biases and implicit and explicit measures of stimulus valence. Addiction, 98, 825-836.

Nathan, P. E. (1985). Aversion therapy in the treatment of alcoholism: Success and failure. Annals of the New York Academy of Sciences, 443, 357-364.

Orford, J. (2001). Addiction as excessive appetite. Addiction, 96, 15-31.

Ostafin, B. D., Palfai, T. P., \& Wechsler, C. E. (2003). The accessibility of motivational tendencies toward alcohol: Approach, avoidance, and disinhibited drinking. Experimental \& Clinical Psychopharmacology, 11, 294-301.

Palfai, T. P., \& Ostafin, B. D. (2003a). Alcohol-related motivational tendencies in hazardous drinkers: Assessing implicit response tendencies using the modified IAT. Behaviour Research and Therapy, 41, 1149-1162.

Palfai, T. P., \& Ostafin, B. D. (2003b). The influence of alcohol on the activation of outcome expectancies: The role of evaluative expectancy activation in drinking behavior. Journal of Studies on Alcohol, 64, 111-119.

Peterson, J. B., Finn, P. R., \& Pihl, R. O. (1992). Cognitive dysfunction and the inherited predisposition to alcoholism. Journal of Studies on Alcohol, 53, 154-160.

Phelps, E. A., O’Connor, K. J., Cunningham, W. A., Funayama, E. S., Gatenby, J. C., \& Gore, J. G. (2000). Performance on indirect measures of race evaluation predicts amygdala activation. Journal of Cognitive Neuroscience, 12, 729-738.

Rather, B. C., Goldman, M. S., Roehrich, L., \& Brannick, M. (1992). Empirical modeling of an alcohol expectancy memory network using multidimensional scaling. Journal of Abnormal Psychology, 101, 174-183.

Robinson, T. E., \& Berridge, K. C. (1993). The neural basis of drug craving: An incentive-sensitization theory of addiction. Brain Research Reviews, 18, 247-291.

Robinson, T. E., \& Berridge, K. C. (2003). Addiction. Annual Review of Psychology, 54, 25-53.

Russell, J. A., \& Carroll, J. M. (1999). On the bipolarity of positive and negative affect. Psychological Bulletin, 125, 3-30. 
Saal, D., Dong, Y., Bonci, A., \& Malenka, R. (2003). Drugs of abuse and stress trigger a common synaptic adaptation in dopamine neurons. Neuron, 37, $577-582$.

Sayette, M. A. (1999). Cognitive theory and research. In K .E. Leonard \& H. T. Blane (Eds.), Psychological theories of drinking and alcoholism (2nd ed., pp. 247-291). New York: Guilford.

Sher, K. J. (1987). Stress response dampening. In H. T. Blane \& K. E. Leonard (Eds.), Psychological theories of drinking and alcoholism (pp. 227-271). New York: Guilford.

Sher, K. J. (1991). Children of alcoholics, a critical appraisal of theory and research. Chicago: University of Chicago Press.

Sher, K. J., \& Gotham, H. J. (1999). Pathological alcohol involvement: A developmental disorder of young adulthood. Development and Psychopathology, 11, 933-956.

Sher, K. J., Walitzer, K. S., Wood, P. K., \& Brent, E. E. (1991). Characteristics of children of alcoholics: Putative risk factors, substance use and abuse, and psychopathology. Journal of Abnormal Psychology, 100(4), 427-448.

Sher, K. J., Wood, M. D., Wood, P. K., \& Raskin, G. (1996). Alcohol outcome expectancies and alcohol use: A latent variable cross-lagged panel study. Journal of Abnormal Psychology, 105, 561-574.

Sherman, S. J., Rose, J. S., Koch, K., Presson, C. C., \& Chassin, L. (2003). Implicit and explicit attitudes toward cigarette smoking: The effects of context and motivation. Journal of Social \& Clinical Psychology, 22, 13-39.

Smolka, M. N., Klein, S., Lemenager, T., Georgi, A., Nikitopoulos, J., Flor, H., et al. (2004, June). Emotional valence of alcohol-related stimuli and cueinduced bold activation. Paper presented at the 27th Annual Scientific Meeting of the Research Society on Alcoholism, Vancouver, BC.

Stacy, A. W. (1995). Memory association and ambiguous cues in models of alcohol and marijuana use. Experimental \& Clinical Psychopharmacology, 3, 183-194.

Stacy, A. W. (1997). Memory activation and expectancy as prospective predictors of alcohol and marijuana use. Journal of Abnormal Psychology, 106, 61-73.

Stacy, A. W., Ames, S. L., \& Knowlton, B. (2004). Neurologically plausible distinctions in cognition and habit relevant to drug abuse prevention. Substance Use \& Misuse, 39, 1571-1623.

Stewart, J., De Wit, H., \& Eikelboom, R. (1984). The role of unconditioned and conditioned drug effects in the self-administration of opiates and stimulants. Psychological Review, 91, 251-268.

Stewart, S. H., \& Conrod, P. J. (in press). Introduction to the special issue on stateof-the-art in cognitive-behavioral interventions for substance use disorders. Journal of Cognitive Psychotherapy.

Stewart, S. H., \& Devine, H. (2000). Relations between personality and drinking motives in young people. Personality and Individual Differences, 29(3), 495-511.

Stewart, S. H., Hall, E., Wilkie, H., \& Birch, C. (2002). Affective priming of alcohol schema in coping and enhancement motivated drinkers. Cognitive Behaviour Therapy, 31, 68-80.

Stormark, K. M., Field, N. P., Hughdahl, K., \& Horowitz, M. (1997). Selective processing of visual alcohol cues in abstinent alcoholics: An approach-avoidance conflict. Addictive Behaviors, 22, 509-519. 


\section{IMPLICIT COGNITIONS AND DIFFERENT ADDICTIONS}

Strack, F., \& Deutsch, R. (2004). Reflective and impulsive determinants of social behavior. Personality and Social Psychology Review, 3, 220-247.

Stritzke, W. G. K., Breiner, M. J., Curtin, J. J., \& Lang, A. (2004). Assessment of substance cue reactivity: Advances in reliability, specificity and validity. Psychology of Addictive Behaviors, 18, 148-159.

Teachman, B. A., \& Woody, S. R. (2003). Automatic processing in spider phobia: Implicit fear associations over the course of treatment. Journal of Abnormal Psychology, 112, 100-109.

Thush, C., \& Wiers, R. W. (2005). Explicit and implicit alcohol-related cognitions and the prediction of current and future drinking in adolescents. Manuscript submitted for publication.

Tiffany, S. T. (1990). A cognitive model of drug urges and drug-use behavior: Role of automatic and nonautomatic processes. Psychological Review, 97, 147-168.

Van den Wildenberg, E., Beckers, M., Van Lambaart, F., \& Wiers, R. W. (2004). Is the strength of implicit alcohol associations correlated with heart rate acceleration after alcohol consumption? Paper presented at the 27th Annual Scientific Meeting of the Research Society on Alcoholism, Vancouver, BC.

White, N. M. (1996). Addictive drugs as reinforcers: Multiple partial actions on memory systems. Addiction, 91, 921-949.

Wiers, R. W., Both, S., Franken, I., Iedema, T., \& Kloosterman, M. (2005c). Unpublished data.

Wiers, R. W., De Jong, P. J., Havermans, R., \& Jelicic, M. (2004). How to change implicit drug-related cognitions in prevention: A transdisciplinary integration of findings from experimental psychopathology, social cognition, memory and learning psychology. Substance Use \& Misuse, 39, 1625-1684.

Wiers, R. W., Ganushchack, L., Van de Ende, N., Smulders, F. T. Y., \& De Jong, P. J. (2003, May/June). Comparing implicit alcohol associations across different rt-measures: The implicit association test (IAT) versus varieties of the extrinsic affective simon task (EAST). Paper presented at the 15th Annual Convention of the American Psychological Society, Atlanta, GA.

Wiers, R. W., Granzier, J., \& Havermans, R. (2005). Context effects on implicit and explicit alcohol-related cognitions. In M. Krank, A. Wall, S. H. Stewart, R. W. Wiers, \& M. S. Goldman (Eds.), Context effects on alcohol cognitions. Alcoholism: Clinical and Experimental Research, 29, 196-206.

Wiers, R. W., Gunning, W. B., \& Sergeant, J. A. (1998). Do young children of alcoholics hold more positive or negative alcohol-related expectancies than controls? Alcoholism: Clinical and Experimental Research, 22, 1855-1863.

Wiers, R. W., Hoogeveen, K. J., Sergeant, J. A., \& Gunning, W. B. (1997). High and low dose expectancies and the differential associations with drinking in male and female adolescents and young adults. Addiction, 92, 871-888.

Wiers, R. W., Sergeant, J. A., \& Gunning, W. B. (2000). The assessment of alcohol expectancies in school children: Measurement or modification? Addiction, 95, 737-746.

Wiers, R. W., Stacy, A. W., Ames, S. L., Noll, J. A., Sayette, M. A., Zack, M., et al. (2002). Implicit and explicit alcohol-related cognitions. Alcoholism: Clinical and Experimental Research, 26, 129-137.

Wiers, R. W., Van de Luitgaarden, J., Van den Wildenberg, E., \& Smulders, F. T. Y. (2005). Challenging implicit and explicit alcohol-related cognitions in young heavy drinkers. Addiction, 100, 806-819. 
Wiers, R. W., Van Woerden, N., Smulders, F. T. Y., \& de Jong, P. J. (2002). Implicit and explicit alcohol-related cognitions in heavy and light drinkers. Journal of Abnormal Psychology, 111, 648-658.

Wiers, R. W., Wood, M. D., Darkes, J., Corbin, W. R., Jones, B. T., \& Sher, K. J. (2003). Changing expectancies: Cognitive mechanisms and context effects. Alcoholism: Clinical and Experimental Research, 27, 186-197.

Wilson, G. T. (1987). Chemical aversion conditioning as a treatment for alcoholism: A re-analysis. Behaviour Research and Therapy, 25(6), 503-516.

Wilson, G. T. (1991). Chemical aversion conditioning in the treatment of alcoholism: Further comments. Behaviour Research and Therapy, 29(5), 415-419.

Wise, R., \& Bozarth, M. (1987). A psychomotor stimulant theory of addiction. Psychological Review, 94, 469-492.

Zack, M., Toneatto, T., \& MacLeod, C. M. (1999). Implicit activation of alcohol concepts by negative affective cues distinguishes between problem drinkers with high and low psychiatric distress. Journal of Abnormal Psychology, 108, 518-531. 